\title{
根际氧含量影响植物生长的生理生态机制研究进展
}

\author{
郑小兰 王瑞娇 赵群法 刘勇鹏 王媛媛 孙治强”
}

河南农业大学园艺学院, 郑州 450002

\begin{abstract}
摘 要 氧是植物生命活动所必需的营养因子, 充足的氧供应才能满足植物正常生长发育的需求, 但频发的洪涝灾害使根系 淹水缺氧成为植物生长过程中经常遭受的非生物胁迫。因此, 了解植物对根际氧含量变化的响应与适应机制对作物的生产及 抗性品种的选育有重要意义。该文对根际氧环境对植物多方面的影响进行了综述, 包括植物的需氧量、氧含量对根际环境的 影响和氧含量对植物的影响等, 并阐明植物在低氧下的伤害与适应机理和植物对低氧信号的感应与信号传导机制, 最后总结 了避免缺氧伤害的措施，同时还提出根际氧含量方面有待进一步探索的问题与研究方向，为后续的研究提供新思路。

关键词＼cjkstart根际氧含量；适应机制；氧感应；内氧浓度；增氧
\end{abstract}

引用格式: 郑小兰, 王瑞娇, 赵群法, 刘勇鹏, 王媛媛, 孙治强 (2017). 根际氧含量影响植物生长的生理生态机制研究进展. 植物生态学报, 41, 805-814. doi: 10.17521/cjpe.2017.0042

\section{Ecophysiological mechanisms of plant growth under the influence of rhizosphere oxygen con- centration: A review}

ZHENG Xiao-Lan, WANG Rui-Jiao, ZHAO Qun-Fa, LIU Yong-Peng, WANG Yuan-Yuan, and SUN Zhi-Qiang* Horticulture College of Henan Agricultural University, Zhengzhou 450002, China

\begin{abstract}
Oxygen is an essential substance for plants, and adequate oxygen supply is necessary for plant growth and developments. As one of the major abiotic threats to plants, frequent floods could lead to oxygen deficiency in the rhizosphere. Therefore, it is important to understand the response and adaptive mechanisms of plants to rhizosphere oxygen concentration for crop productions and breeding of resistant varieties. This review shed light on the impacts of rhizosphere oxygen contents on plants from multiple perspectives. We also demonstrated the injury and acclimations caused by oxygen deficiency and the mechanism of low-oxygen signaling. We finally summarized methods to avoid oxygen deficit and prospect of further studies.
\end{abstract}

Key words rhizosphere oxygen content; adaptation mechanism; oxygen signaling; internal oxygen concentration; aeration

Citation: Zheng XL, Wang RJ, Zhao QF, Liu YP, Wang YY, Sun ZQ (2017). Ecophysiological mechanisms of plant growth under the influence of rhizosphere oxygen concentration: A review. Chinese Journal of Plant Ecology, 41, 805-814. doi: 10.17521/cjpe.2017.0042

氧是绿色高等植物维持正常生理代谢和生长 发育的必要条件, 在氧化磷酸化能量代谢过程中 $\mathrm{O}_{2}$ 作为呼吸链电子传递的最终唯一受体, 为植物细胞 生长提供能量(Morard \& Silvestre, 1996)。植物活细 胞生长代谢需要合适的氧浓度, 但在作物生产中, 常常因洪涝灾害、灌溉不当、基质栽培中根垫形成 或营养液溶解氧过低等导致根际供氧不足, 形成缺 氧或低氧逆境(Drew, 1997), 从而对作物的生长、产 量和品质等造成不利影响, 严重时可使植株死亡 (王文泉和张福锁, 2001; 郭世荣, 2011)。当根系 $\mathrm{O}_{2}$ 供应不足时, 植株根系有氧呼吸受到影响或抑制,
能量代谢紊乱, 进而引起一系列生理问题, 如根系 吸收水分、养分减少, 光合作用速率降低等, 最终影 响植株的正常生长和发育, 因此氧是作物生产中重 要的营养因子。近年来, 我国洪涝灾害频发, 灾害程 度更甚, 年平均受灾面积达 $97000 \mathrm{~km}^{2}$ 以上(陈䒯等, 2011)，而且全国农作物受灾面积呈增加趋势(王艳 君等, 2014), 其中以黄淮平原和长江中下游最为严 重。涝渍对植物的本质伤害是由于土壤水分过多导 致的根系缺氧, $\mathrm{O}_{2}$ 在水中的扩散速率仅是空气中的 $1 / 10000$, 土壤含水量较高, $\mathrm{O}_{2}$ 通过水层向土壤深层 扩散的速度显著减慢, 土壤中 $\mathrm{O}_{2}$ 消耗与供应不平衡,

收稿日期Received: 2017-02-23 接受日期Accepted: 2017-06-01

* 通信作者Author for correspondence (E-mail: sunzhiqiang1956@sina.com) 
致使土壤中氧含量显著降低(Armstrong \& Drew, 2002)。根际低氧或缺氧胁迫严重制约作物的生长, 探索植物对低氧环境的生理生化响应及分子机制逐 渐成为热点, 同时越来越多的学者开始探索增氧措 施对植物生长的影响及氧含量增加对作物产量的促 进作用。本文就植物对根际氧环境的响应与适应机 制、植物细胞内氧浓度的变化及增氧措施的相关研 究进行综述, 为后续研究提供参考。

\section{1 植物的需氧量}

对高等植物来说，一般情况下土壤空气中 $\mathrm{O}_{2}$ 的 含量达到 $15 \%$ 才能满足植物呼吸作用的需要。作物 根系对土壤中 $\mathrm{O}_{2}$ 的最低要求因作物而异 (棉花 (Gossypium hirsutum) 3\%, 玉米(Zea mays) 6\%, 小 麦(Triticum aestivum) 5\%), 稻田土壤中氧含量至少 在3\%-5\%才能满足水稻(Oryza sativa)根系对氧的正 常吸收, 当氧含量低于 $5 \%$ 时, 大多数作物根系停止 生长, 所以根系氧含量在 $5 \%-10 \%$ 以上时才能生长 良好(朱鹤健, 1992)。日本学者对水稻的需氧量进行 精细定量研究后, 确定水培下水稻不同时期的需氧 量：分藍期为 $0.27-0.79 \mathrm{mg} \cdot \mathrm{g}^{-1} \cdot \mathrm{h}^{-1}$, 拔节期为 $0.88-0.95 \mathrm{mg} \cdot \mathrm{g}^{-1} \cdot \mathrm{h}^{-1}$, 孕穗期为 $0.98-1.07 \mathrm{mg} \cdot \mathrm{g}^{-1} \cdot \mathrm{h}^{-1}$, 抽穗期为 $0.93 \mathrm{mg} \cdot \mathrm{g}^{-1} \cdot \mathrm{h}^{-1}$, 齐穗期为 $0.85 \mathrm{mg} \cdot \mathrm{g}^{-1} \cdot \mathrm{h}^{-1}$, 成熟期为 $0.68 \mathrm{mg} \cdot \mathrm{g}^{-1} \cdot \mathrm{h}^{-1}$ (Gunther, 1987)。在水培状 态, 溶液中氧浓度为 $0 \mathrm{mg} \cdot \mathrm{L}^{-1}$ 时被称为极度缺氧, 含量少于 $3 \mathrm{mg} \cdot \mathrm{L}^{-1}$ 时被称为低氧, 溶解氧的浓度达 到 $4 \mathrm{mg} \cdot \mathrm{L}^{-1}$ 以上才可满足多数植物生长的需要 (Rong \& Tachibana, 1997), 另有研究表明营养液溶 氧量低于 $3 \mathrm{mg} \cdot \mathrm{L}^{-1}$ 时水培番茄(Lycopersicon esculentum)产生氧缺乏症状(Bonachela et al., 2010)。

\section{2 根际氧含量的主要影响因子}

根际环境由土壤中固、液、气三相相互作用与 微生物的活动共同构成, 因此土壤结构、孔隙度、 含水量是影响根际氧含量的重要因素(Nakano, 2007; 裴鹏刚等, 2013)。土壤孔隙度大、含水量低, 有利 于土壤空气与大气交换, 土壤中氧含量较高; 然而 土壤淹水, 空气只能通过土壤孔隙水进入土壤, 其 扩散速率是干土中的 $1 / 10000$, 土壤淹水 6-10 h内, $\mathrm{O}_{2}$ 含量可降至接近于0 (朱鹤健, 1992)。同时, 根系
和其周围好氧微生物的呼吸代谢也会消耗根际环境 中的 $\mathrm{O}_{2}$, 使氧含量降低。温度也是影响氧含量的因 子之一, 当温度降低、土壤呼吸减慢时, 水中氧浓度 下降很缓慢。有研究表明在冬季用黏土种植的谷物 水淹后, 土深 $20 \mathrm{~cm}$ 处的溶解氧浓度降低 0.02 个大气 压需要 13 天, 但是在春季这个过程只需要 3.5 天 (Blackwell \& Ayling, 1980)。Holtman等(2005)的研究 表明冬季微生物呼吸耗氧很低, 在4月份耗氧明显 增加，营养液中的氧很快被完全消耗，根系开始遭 受缺氧胁迫。因此, 在水培作物时, 营养液中微生物 呼吸及液温是根际氧含量主要的影响因子。

\section{3 根际氧含量与土壤养分和植物病害的关系}

土壤中氧环境和土壤养分息息相关。在缺氧的 土壤中好氧微生物活动被抑制, 有机物的分解减慢, 使得植物可利用的营养物质减少; 同时戻氧微生物 的活动增强, 产生许多有毒害作用的物质(陈利军 等, 2002)。例如厌氧微生物能将硝酸盐 $\left(\mathrm{NO}_{3}{ }^{-}\right)$中的 氮通过一系列中间产物 $\left(\mathrm{NO}_{2}-\mathrm{NO} 、 \mathrm{~N}_{2} \mathrm{O}\right)$ 还原为氮 气分子 $\left(\mathrm{N}_{2}\right)$ 获得能量。当环境变得有较强还原性时, 厌氧微生物还可将 $\mathrm{Fe}^{3+}$ 还原为 $\mathrm{Fe}^{2+}$, 持续缺氧会让 土壤中 $\mathrm{Fe}^{2+}$ 积累过多从而造成毒害。还有些厌氧微 生物能把 $\mathrm{SO}_{4}{ }^{2-}$ 还原为 $\mathrm{H}_{2} \mathrm{~S}, \mathrm{H}_{2} \mathrm{~S}$ 可破坏呼吸作用 (Taiz \& Zeiger, 2010)。土壤通气良好, 则 $\mathrm{O}_{2}$ 充足, 这 会促进好氧微生物的活动和繁殖, 从而加速有机质 分解, 土壤矿质化加快, 有效养分得到充分供应, 利于植物生长, 含氮有机物质氨化和硝化作用产生 的硝酸盐也能被植物有效吸收(张莹莹等, 2011)。

土壤淹水会加重病害程度, 使植物更易感病 (Wilcox \& Mircetich, 1985)。淹水缺氧下，根系损伤 更易被疫霉属病菌侵染，同时根系分泌物的增加利 于病菌孢子生存(Kuan \& Erwin, 1980)。同时，低氧 环境会抑制植物感病后积极有效的防御反应，在 $1 \%$ 的 $\mathrm{O}_{2}$ 浓度下踠豆(Pisum sativum)和大豆(Glycine max) 的植物抗毒素的生物合成被严重抑制 (Cruickshank \& Perrin, 1967), 缺氧下的番茄也不再 继续合成植物抗毒素(Alves et al., 1979)。酚氧化酶 需要分子氧使特定的病菌失活, 并形成物理屏障阻 止其他病菌进入，而缺氧在一定程度上抑制了这个 过程(Drew \& Lynch, 1980)。 


\section{4 植物适应根际氧含量变化的生理及分子 机制}

\section{1 根际低氧对植物的伤害与其适应机理}

\subsection{1 种子厌氧萌发}

水稻种子是少数几个能在严格缺氧环境中萌 发的植物种子之一, 但是这种萌发和早期的生长是 以牺牲萌发后根系和第一片叶的生长为代价的。种 子在低氧环境中萌发, 有氧呼吸被严重抑制, 为满 足生长所需的ATP, 不得不消耗储备的能量, 加速 淀粉分解，同时肧芽鞘伸长以便快速伸出水面接触 空气(Abdolhamid et al., 2010; 陈孙禄等, 2012)。 $C I P K 15$ 是调控水稻种子低氧环境萌发的关键基因, CIPK15表达蛋白可促进淀粉酶(Ramy3)基因表达, 从而增加 $\alpha$ 淀粉酶含量, 促使淀粉分解成葡萄糖, 为种子的萌发提供能量, 而且失去 CIPK15的突变 体种子能够在空气中发芽而在水下不能发芽, 这表 明种子内糖耗尽会消耗胚乳储备的能量来满足嫩芽 的生长(Ismail et al., 2010)。

\subsection{2 低氧对根系的伤害及根系的形态适应}

根系是低氧胁迫受害的直接器官。缺氧时根内 能量代谢紊乱, 有氧呼吸减慢或停止, 无氧呼吸增 强, 造成根系组织细胞能量缺乏。在极度缺氧情况 下, 细胞液泡中的 $\mathrm{H}^{+}$逐渐渗透到细胞质中使细胞质 $\mathrm{pH}$ 值降低。酸性条件下, 乳酸脱氢酶活性被抑制, 并激活了丙酮酸脱羧反应, 造成产能减少, ATP的亏 缺又会减慢液泡膜上ATPase将 $\mathrm{H}^{+}$泵至液泡内的速 度, 因此造成细胞质酸化, 而细胞质酸化是造成细 胞损伤或死亡的主要原因(Drew, 1997)。同时无氧呼 吸的产物, 如乳酸、乙醇、乙醛等积累到一定量也 会对细胞产生毒害作用, 这势必会对根系组织的正 常生理功能造成影响。因此, 缺氧下根组织吸收及 运输水分、养分明显减慢, 生长发育迟缓。

通气组织是植物对低氧或淹水胁迫的一种适 应方式, 无论湿生还是旱生植物水淹缺氧都会诱导 通气组织形成(Colmer \& Voesenek, 2009)。皮层细胞 程序化死亡, 然后消溶最终形成一个通气腔(通气 组织), 这不仅有助于 $\mathrm{O}_{2}$ 运输到根际, 还减少了耗氧 细胞数量, 同时, 消溶的皮层细胞还为剩余的细胞 提供营养。淹水下植物根系外皮层凯氏带上木质素 和木栓质积累增多, 然后形成一个横向阻挡层以最 大限度减少根内氧径向扩散到外部(Bramley et al.,
2010)。这种木栓化和木质化的外皮层障碍可有效地 阻止氧从通气组织向根外扩散, 减小径向氧损失, 利于维持细胞内氧浓度。在长期的低氧或淹水条件 下，植物为了生存还会在根茎基部产生不定根，替 代死亡或受到伤害的初生根吸收水分和养分, 并起 支持固定作用，促进植物生长。不定根与茎叶的空 腔和细胞间隙相通, 形成 $\mathrm{O}_{2}$ 向体内扩散的通道, 减 少了 $\mathrm{O}_{2}$ 扩散的距离, 缓解低氧对植物的伤害, 这也 反映了植物对低氧的适应能力(Sauter, 2013)。淹水 组织内乙烯合成和积累增加, 诱导不定根原基的生 长，而上部节位不定根原基因缺乏乙烯信号诱导不 能产生不定根(Negi et al., 2009)。有研究表明乙烯在 促进番茄产生不定根的同时抑制侧根的形成，这有 利于茎生根的产生(Laura et al., 2010)。

\subsection{3 低氧对茎叶的伤害及其适应}

缺氧的根系组织吸收和运输水分受限, 而一旦 根不能吸收营养离子或将营养离子运到木质部再到 幼芽, 将很快影响到地上组织生长所需的营养供给, 这样较老叶片韧皮部中可移动元素 $(\mathrm{N} 、 \mathrm{P} 、 \mathrm{~K})$ 就会 进入幼嫩叶片, 致使其出现过早衰老现象; 根部水 通透性下降, 会使叶片水势减小和萎蒸, 气孔关闭 (Taiz \& Zeiger, 2010)。有研究表明低氧条件下叶绿 体活性降低、叶片失绿、碳水化合物运输下降, 光 合酶的活性受到抑制，导致叶片光合作用能力下降， 植物新叶形成和生长受阻, 生长势减弱, 植株变矮 小(Ashraf \& Harris, 2013); 长期的低氧胁迫使叶绿 体内类囊体膜降解，部分线粒体膜系统也受到损坏 (Ladygin, 1999)。

根系低氧时茎基或下胚轴肥大是草本植物适 应低氧的普遍现象。一般植物长期淹水, 细胞排列 变疏松, 组织间隙增大, 茎基变粗, 并在地表形成 不定根, 有的甚至形成纺锤状茎基, 茎基皮孔增生 则有助于逆境下的气体交换和排除体内毒素 (Vasellati et al., 2001)。有些湿生植物具有根茎叶相 贯通的通气组织, 这可以改善氧运输, 缓解根系的 缺氧状况(Huang et al., 1994)。大豆茎基部皮孔完全 淹水时, 水下茎通气组织中氧分压从 $17.5 \mathrm{kPa}$ 逐渐 降至7.6 kPa, 而解除淹水, 皮孔恢复接触空气, 氧 分压很快恢复至14-17 kPa，通过茎皮孔输入 ${ }^{18} \mathrm{O}_{2}$ 后， 在根内提取到的 ${ }^{18} \mathrm{O}$ 显著增加，说明皮孔运输的 $\mathrm{O}_{2}$ 维持了根系的呼吸(Shimamura et al., 2011)。有些湿 生植物淹水时其组织可感应内源乙烯，刺激叶柄和 
茎伸长, 促使叶片快速露出水面, 进行光合作用, 但这似乎不适合低地旱作的水稻生存, 因为过度的 伸长会引起倒伏和水位回落后死亡(Setter \& Datta, 1997)。根部缺氧能够刺激下部较老和萎蒸的叶片产 生脱落酸(ABA), 然后 $\mathrm{ABA}$ 被运输到幼嫩、光合作 用活跃及膨胀的叶片中, 最终导致其气孔关闭 (Zhang, 1994)。植物对根际低氧胁迫的形态适应还 表现为气孔密度增加、叶片变厚且小、外表皮及叶 肉细胞的角质层和细胞壁变厚等。

\section{2 增氧对植物生长的影响}

根际低氧常常发生且不利于植物生长发育, 许 多学者开始探究增加根际氧含量的措施及增氧对植 物的影响。前人研究表明根系通气增氧会引起相关 基因表达变化从而降低乙烯的产生, 影响通气组织 的形成, 增氧处理下根内与细胞程序化死亡(PCD) 相关基因 OsBphi008a 和 OsPDCD5 表达下调, OsBphi008a的表达模式在乙烯合成中有积极作用, OsPDCD5的表达也与 $\mathrm{PCD}$ 相关, 在水稻通气组织 形成中表现出积极作用(Hu et al., 2011)。对水培和 淹水的番木瓜(Carica papaya)进行通气和施用 $\mathrm{H}_{2} \mathrm{O}_{2}$ 或 $\mathrm{CaO}_{2}$ 后可缓解植株低氧胁迫症状, 并促进淹水过 后植株的复苏(Thani et al., 2016)。增加水培营养液 溶氧量提高了番茄根抗性(Chérif et al., 1997); 根系 通空气可增加水稻不定根长度、生物量和总吸收面 积, 促进水稻生长(徐春梅等, 2012; Jing, 2015); 在 $\mathrm{N}$ 含量有限的条件下提高根系氧浓度可增加 $\mathrm{N}$ 吸收, 根系全氮含量升高, 且增氧与氮形态存在一定的互 作效应(Jing, 2015)。也有研究发现溶氧饱和下常规 水培不利于水稻生长和 N积累(赵锋等, 2012), 过高 地增加根际含氧量 (大于 $16 \mathrm{mg} \cdot \mathrm{L}^{-1}$ ), 植株的相对生 长率并没有显著增加(Nichols et al., 2002), 而溶氧 量高于 $30 \mathrm{mg} \cdot \mathrm{L}^{-1}$ 时会降低植株生长率(Zheng et al., 2007)。因此, 适宜的根际通气增氧对植物生长有利, 但过高地增加氧浓度对植物生长的促进作用却没有 明显增强。

\section{3 植物细胞内氧浓度的变化}

植物是专性需氧的生物体, 而关于植物与氧的 研究通常集中在植物对外部氧浓度变化的响应, 对 于植物组织内部氧浓度的问题少有探究。植物实际 上有一种驱使自己进入缺氧的倾向, 即使在 $\mathrm{O}_{2}$ 充足 的环境中, 代谢旺盛的组织也可能面临着缺氧, 尤 其是那些细胞间隙很小且细胞没有液泡或者位于组
织中心的细胞, 阻止其缺氧需要一个很大的氧浓度 梯度来驱使 $\mathrm{O}_{2}$ 足够快地进入中心组织, 弥补其耗 氧。同时, 植物体内缺乏有效的 $\mathrm{O}_{2}$ 的输送系统, 短 暂的洪涝, 土壤微生物活动都可导致根内 $\mathrm{O}_{2}$ 快速减 少(Geigenberger, 2003)。有研究表明即使外部 $\mathrm{O}_{2}$ 充 足 $(21 \%)$, 葲麻(Ricinus communis)韧皮部组织内 $\mathrm{O}_{2}$ 含量也只有 $5 \%-6 \%$ (Dongen et al., 2003), 根分生组 织内是 4\%-10\% (Ober \& Sharp, 1996), 拟南芥 (Arabidopsis thaliana)和油菜(Brassica campestris)的 角果内是 $6 \%-12 \%$ (Johannes, 1960)。在体积较大的 贮藏器官(如: 苹果(Malus pumila)(Magness, 1920)、 香蕉 $($ Musa $\times$ paradisiaca)(Banks, 2002)和生长中的 马铃薯 (Solanum tuberosum)(Geigenberger et al., 2000))内部氧浓度呈梯度式下降, 甚至降到低氧水 平，而采收后内氧浓度明显增加，这可能是由于采 收后其呼吸消耗减少, 当种子见光后, 其内氧浓度 也增加。组织细胞内缺氧抑制氧化磷酸化, 细胞不 得不通过发酵途径获得ATP, 而此途径损害细胞的 代谢和功能, 且严重降低 ATP 的产生效率 (Rolletschek et al., 2002)。植物进化了一系列代谢机 制来适应组织内低氧，比如通过改变酶活性调节呼 吸耗氧来避免缺氧, 但低氧信号在植物体内的感应 传导还未获得完整的解释。

\section{4 植物对氧的感应与信号传导}

细胞能够直接或间接地感应体内氧水平, 从而 产生一系列适应性反应使其在缺氧下存活。在缺氧 和无氧状态下, 动物和真菌的一些基因能直接参与 氧感应，但在植物体内还未发现类似的基因同系物， 因此, 植物可能有独特的直接感应缺氧的机制, 或 者只利用间接的感应机制。间接的感应机制包括细 胞质 $\mathrm{pH}$ 值降低、 $\mathrm{Ca}^{2+}$ 浓度上升、活性氧(ROS)和一 氧化氮(NO)的产生, 以及因腺苷酸(ATP、ADP和 $\mathrm{AMP}$ )、碳水化合物消耗和丙酮酸水平变化引起的能 量状态的改变(Bailey-Serres \& Chang, 2005)。

SnRK1s (Sucrose non-fermenting 1(SNF1)-related kinase)作为 SNF1家族的一个分支, 是植物的能量感 应器, 且与低氧响应密切相关。淹水缺氧下水稻种 子萌发时, 蔗糖耗尽会激活能量感应器SnRK1A, 从而激活类钻调神经磷酸酶B互作激酶, 这一信号 转导上调 $\alpha$ 淀粉酶基因表达, 促使种子分解淀粉, 满足水下嫩芽的生长(Wei et al., 2009); 而且低氧条 件下拟南芥中激酶KIN10和KIN11限制能量消耗。 
理论上, 当ATP水平降低时能量消耗减少对植物有 利, 在低氧胁迫下, mRNAs选择性表达和沉默正是 植物避免能量浪费的一种方式(Branco-Price et al., 2008)。在其他真核生物中已被证实, SnRK1s和雷帕 霉素激酶靶蛋白能够调控细胞内一些mRNAs子集 沉默, 如多种核糖蛋白编码基因和转录因子 (Baena-Gonzalez, 2010)。

$\mathrm{Ca}^{2+}$ 和 $\mathrm{NO}$ 作为胞内第二信使, 参与氧信号传 导, 且 $\mathrm{Ca}^{2+}$ 传导途径研究较为透彻。有研究表明, 玉 米在开始缺氧的几分钟内, 胞质浓度 $\mathrm{Ca}^{2+}$ 升高, 诱 导细胞乙醇脱氢酶(ADH)和蔗糖合成酶(SS) mRNA 水平上升, 应用阻断 $\mathrm{Ca}^{2+}$ 升高的试剂后发现, 缺氧 诱导的 $\mathrm{ADH}$ 和 $\mathrm{SS}$ 基因表达被抑制，这大大增强了 玉米植株对缺氧的敏感性; 对玉米县浮培养时, 降 低 $\mathrm{O}_{2}$ 浓度诱导胞内 $\mathrm{Ca}^{2+}$ 浓度迅速增加, 恢复供氧后 $\mathrm{Ca}^{2+}$ 又恢复到正常水平, 并且 $\mathrm{Ca}^{2+}$ 浓度变化优先于 基因表达和生理生化变化 (Rhoads \& Subbaiah, 2007)。另有研究(Liu et al., 2004)表明在遭受低氧胁 迫时, 细胞质 $\mathrm{pH}$ 值下降和 $\mathrm{ATP}$ 缺乏引起 $\mathrm{Ca}^{2+}$ 响应, 胞内储钙体的 $\mathrm{Ca}^{2+}$ 通道打开, 细胞内 $\mathrm{Ca}^{2+}$ 浓度急 剧增加, 并与钙调蛋白 $(\mathrm{CaM})$ 结合诱导下游生理生 化代谢途径改变, 维持细胞壁、细胞膜及膜蛋白的 稳定。

线粒体也有助于氧信号的感应和传导。当植物 从正常氧环境转入低氧环境, 线粒体内产生 NO、活 性氧(ROS)响应低氧胁迫 (Blokhina \& Fagerstedt, 2010)。缺氧条件下, 依赖硝酸盐而产生的NO和线 粒体对NO和ROS水平的精细调控是减缓呼吸、防止 组织进入完全缺氧状态的主要调控机制 (Igamberdiev et al., 2010)。缺氧的线粒体利用NADH 和亚硝酸盐(作为电子的接收者)生成ATP的同时也 会产生NO, 因此, 缺氧组织积累较多NO。紫苜宿和 细胞培养的玉米在低氧条件下均观察到 $\mathrm{NO}$ 的积累 (Dordas et al., 2004)。HIF-1是第一个从高等生物中 分离出来的厌氧转录因子, 其与厌氧基因的结合能 力及转录活性被低氧诱导, HIF-1的活性受ROS浓度 的调控, 而ROS可作为第二信使参与抗氧化过程的 调节(Wang \& Semenza, 1993)。在缺氧条件下, 黄嘌 呤氧化还原酶可以利用缺氧发酵积累的乙醛和ATP 分解代谢产生的次黄嘌呤作为电子供体进行 $\mathrm{O}_{2}$ 的 初级活化, 进而产生 $\mathrm{O}_{2}{ }^{-}$和 $\mathrm{H}_{2} \mathrm{O}_{2}$, 诱导抗氧化途径产 生, 减缓缺氧造成的伤害(Godber et al., 2000)。
植物所特有的VII组乙烯响应因子(ERFs) 是感 应低氧和淹水胁迫的关键蛋白, 而且VII组ERFs调 控水稻在淹水胁迫下的生存能力 (Gibbs et al., 2011)。拟南芥中VII组ERFs家族有 5 个成员(HRE1、 HRE2、RAP2.2、RAP2.12、RAP2.3), 它们是低 $\mathrm{O}_{2}$ 传感机制的关键组成部分, 也是 $\mathrm{N}$ 端法则水解途径 (NERP)的底物(Licausi et al., 2011)。拟南芥VII组 ERFs的 $\mathrm{N}$ 末端第二个氨基酸为半胱氨酸, 在正常氧 条件下, 半胱氨酸氧化会导致ERF蛋白降解, 而低 氧或缺氧则使 $\mathrm{ERF}$ 蛋白稳定, 这促进激活与厌氧代 谢及淹水生存相关的基因, 尽管ERFs的直接靶基因 还未见报道(Gibbs et al., 2011)。当 $\mathrm{N}$ 末端标记的 RAP2.12组成型表达时, 许多核心低氧响应基因转 录高表达, 而未标记的RAP2.12同样表达时, 低氧 响应基因没有高表达(Licausi et al., 2011)。在NERP 中有基因缺陷的突变体低氧响应基因转录超表达, 使其种子萌发和幼苗存活率高于野生型。同时, 在 正常氧水平下, 合成和翻译RAP2.12的蛋白被酰基 辅酶A 结合蛋白 $(\mathrm{ACBP} 1 / 2)$ 隔离在质膜外, $\mathrm{O}_{2}$ 被剥夺 可促进RAP2.12进入细胞核内同时激活低氧响应基 因。RAP2.2、2.3和2.12的表达很可能是 $\mathrm{O}_{2}$ 的感受器, 极度低氧在影响下游目标前会先诱导HRE1/2活化 转录((Licausi et al., 2010)。

\section{5 避免低氧或缺氧伤害的途径}

\section{1 增加氧含量的农艺措施}

在田间生产时，一般采取深耕翻土、中耕松土、 合理灌溉排水、施用有机肥改良土壤质地等农艺措 施来改善土壤结构, 增加土壤氧含量。现今, 新兴的 增氧灌溉开始受到人们青崃。增氧灌溉是通过向灌 溉水中加气, 直接向作物根系输送氧来优化根际气 体环境, 从而促进作物生长、提高产量的高效节水 灌溉技术。向灌溉水中增氧的方式有3种, 即机械加 气、化学溶氧和微纳米气泡曝气。机械加气是常用 的增氧灌溉方式, 但是效率较低, 难以使灌溉水溶 氧值迅速增加。化学溶氧是向灌溉水体中加入过氧 化物, 如 $\mathrm{H}_{2} \mathrm{O}_{2} 、 \mathrm{CaO}_{2}$ 等, 使其在水中分解释放 $\mathrm{O}_{2}$ 从 而提高水体中溶解氧含量, 但是 $\mathrm{H}_{2} \mathrm{O}_{2}$ 有一定的腐蚀 性, 化学增氧剂是否对植物产生某些不良影响, 还 有待进一步研究(薛晓莉等, 2017)。微纳米气泡曝气 是利用微纳米气泡快速发生装置产生直径在数百纳 米至10 $\mu \mathrm{m}$ 左右的空气(或氧气)泡溶入灌溉水或营 
养液中, 这能快速使水体富氧, 改善根际溶氧环境 (金强, 2008)。这种微纳米气泡水因其充足的 $\mathrm{O}_{2}$ 含量 和特殊的生物生理活性, 如带电性、氧化性、杀菌 性等, 对植物生长有促进作用(Park et al., 2010; 薛 晓莉等, 2017)。

在营养液栽培中是通过空气和营养液接触而 增加溶解氧含量, 例如气泡法、滴雾法、流液法、 雾根法、湿根法等。在雾培法、湿根法中将空气混 入特制的供液口, 产生气泡和水滴或雾滴, 同时对 贬液池搅拌, 增加溶氧量; 营养液膜法(NET)通过 营养液在流动中与空气接触而提高氧浓度。

\section{2 培育耐低氧品种}

培育和篎选耐低氧的作物品种是解决低氧问 题最为直接和易于推广的措施。淹涝一直被认为是 导致根系缺氧的直接原因, 因此对耐淹涝品种的篮 选培育也属于耐低氧品种的篎选范围。目前已有大 量耐淹涝和耐低氧品种篮选工作, 有研究对根际低 氧胁迫下猕猴桃(Actinidia) 实生苗 (米银法, 2009) 和 苹果砧木(白团辉等, 2008)进行耐性评价, 不同品种 对低氧逆境的耐性有显著差异, 猕猴桃幼苗抗低氧 能力和内源激素的平衡调节机制密切相关, 抗性强 的美味猕猴桃(Actinidia deliciosa) 比抗性弱中华猕 猴桃(Actinidia chinensis)的ABA增加幅度小, 内源 激素平衡遭受的破坏程度较轻; 不耐低氧的变叶海 棠(Malus toringoides)的细胞膜受到的氧化伤害比耐 低氧的平邑甜茶(Malus hupehensis)更严重, 其抗氧 化系统的防御能力则相反。目前多个耐低氧相关基 因逐渐被发现, Sub1A和CIPK15基因可以使不同生 育期受低氧胁迫的水稻表现出耐盐性状, CIPK15是 种子在缺氧环境萌发成活的关键基因, 而水稻营养 生长阶段则是由Sub1基因调控, Sub1位点和Sub1A 耐低氧基因分子标记的有效性为采用分子标记辅助 技术来培育耐低氧性强的品种提供了可能(Wei et al., 2009)。

\section{3 施用外源物质提高耐性}

近年来, 施用外源植物生长调节剂缓解植物低 氧伤害已成为研究热点。适时科学地应用外源植物 生长调节剂可有效地减轻低氧伤害, 提高植株耐低 氧能力。低氧胁迫下对网纹甜瓜(Cucumis melo var. reticulatus)叶片喷施 $\gamma$-氨基丁酸(GABA)后, 植株抗 氧化酶活性增加, 体内 ROS含量降低, 增强了植株 的耐低氧能力(高洪波和郭世荣, 2004)。营养液中添
加多胺或在叶片上喷施多胺可增加黄瓜(Cucumis sativus)植株的耐低氧性(汪天等, 2005)。另有研究表 明外源油菜素内酯(马月花等, 2015)、亚精胺(贾永霞, 2009)、腐胺(贾永霞等, 2008)等均可在一定程度上提 高植株的低氧耐性, 减轻低氧伤害。因此合理选用 一些外源物质，通过对栽培作物浸种、叶面喷施、 根际施用等, 调节植物生理代谢, 成为缓解和克服 低氧胁迫的简单、有效的调控途径。

\section{6 问题和展望}

近年来, 国内外研究者对植物厌氧适应与响应 进行了广泛深入的研究, 且取得了较大进展, 如低 氧对植物的伤害机理、植物对低氧的响应与适应机 制、低氧信号传导因子与相关调控基因的逐渐发现、 增加根际氧浓度措施等, 但仍有较多问题有待进一 步深入研究。

首先, 低氧研究材料需要多样化。不同物种的 植物对低氧或缺氧的耐受性不同, 虽然目前对水稻 在淹水和低氧胁迫下的调控机制研究已较为深入, 但其他物种之间耐低氧性的调控机制还鲜为人知, 而且对木本植物的研究远远落后于草本植物。随着 全球气候异常, 局部地区暴雨频发, 森林也会遭遇 淹水低氧胁迫，同时淹水胁迫会影响果树的产量和 果实品质, 而对果树淹水胁迫的生化及分子机理研 究还较少。其次, 植物对低氧信号的感应和具体转 导途径还有待深入全面探究。尽管我们已经了解水 稻和拟南芥的VII组ERFs 调控GA的响应和碳水化 合物的消耗使植株在淹涝条件下生存, 但这并不能 解释其他物种或者其他变量条件下所有的耐涝机理, 对低氧的关键感应、传导因子的研究应包括作物、 野生物种和应用最先进的基因组学技术等。很多湿 生植物对淹水有良好的适应性, 而且一些陆生植物 在湿地、河滩和盐沼泽上也能茁壮成长, 发掘、鉴 定这些植物中更多的低氧感应与传导基因, 探索植 物系统的低氧信号传导途径将是今后的一个研究热 点。同时，完善的厌氧反应基因库有利于用转基因 培育抗低氧胁迫的植物材料。

另外, 对植物不同生长时期的需氧规律还知之 甚少。一定程度上提高根际氧浓度对植株的生长有 利, 但过高地增加氧浓度是否对植株造成高氧胁迫, 对植物生长的最适氧浓度还鲜有研究。目前的研究 大多局限于幼苗水培和盆栽试验, 处理时间短, 缺 
乏对植物整个生育期内根际氧含量变化的实时监测, 且不同溶氧量对作物产量构成因子及其品质的影响 分析和根系增氧对植物生化及分子影响机制很少有 人探讨，因此探究作物田间需氧特性和适宜的增氧 浓度对其生产实践具有重要指导价值, 也是作物稳 产高产的需要。

\section{基金项目 国家重点基础研究发展计划(2016YED-} 0201008)。

\section{参考文献}

Abdolhamid AS, Septiningsih EM, Mackill DJ, Ismail AM (2010). QTLs associated with tolerance of flooding during germination in rice (Oryza sativa L.). Euphytica, 172, $159-168$.

Alves LM, Heisler EG, Kissinger JC, Patterson JI, Kalan EB (1979). Effects of controlled atmospheres on production of sesquiterpenoid stress metabolites by white potato tuber. Plant Physiology, 63, 359-362.

Armstrong W, Drew MC (2002). Root growth and metabolism under oxygen deficiency. In: Waisel Y, Eshel A eds. Plant Roots: The Hidden Half. 3rd edn. Marcel Dekker, New York. 729-761.

Ashraf M, Harris PC (2013). Photosynthesis under stressful environments: An overview. Photosynthetica, 51, 163-190.

Baena-Gonzalez E (2010). Energy signaling in the regulation of gene expression during stress. Molecular Plant, 3, 300313.

Bai TH, Ma FW, Li CY, Shu HR, Han MY, Wang K (2008). Physiological responses and analysis of tolerance of apple rootstocks to root-zone hypoxia stress. Agricultural Sciences in China, 41, 4140-4148. (in Chinese with English abstract) [白团辉, 马锋旺, 李翠英, 束怀瑞, 韩明玉, 王昆 (2008). 苹果砧木幼苗对根际低氧胁迫的生理响 应及耐性分析. 中国农业科学, 41, 4140-4148.]

Bailey-Serres J, Chang R (2005). Sensing and signaling in response to oxygen deprivation in plants and other organisms. Annals of Botany, 96, 507-518.

Banks NH (2002). Evaluation of methods for determining internal gases in banana fruit. Journal of Experimental Botany, 92, 572-580.

Blackwell PS, Ayling SA (1980). Changes in aeration following transient waterlogging of sandy loam and clay soils cropped with winter cereals. Agricultural Research Council Letcombe Laboratory Annual Report, 35-38.

Blokhina O, Fagerstedt KV (2010). Oxidative metabolism, ROS and NO under oxygen deprivation. Plant Physiology and Biochemistry, 48, 359-373.

Bonachela S, Quesada J, Acuña RA, Magán JJ, Marfà O (2010). Oxyfertigation of a greenhouse tomato crop grown on rockwool slabs and irrigated with treated wastewater: Oxygen content dynamics and crop response. Agricultural Water Management, 97, 433-438.

Bramley H, Turner NC, Turner DW, Tyerman SD (2010). The contrasting influence of short-term hypoxia on the hydraulic properties of cells and roots of wheat and lupin. Functional Plant Biology, 37, 183-193.

Branco-Price C, Kaiser KA, Jang CH, Larive CK, Bailey-Serres J (2008). Selective mRNA translation coordinates energetic and metabolic adjustments to cellular oxygen deprivation and reoxygenation in Arabidopsis thaliana. The Plant Journal, 56, 743-755.

Chen LJ, Wu ZJ, Jiang Y, Zhou LK (2002). Response of N transformation related soil enzyme activities to inhibitor applications. Chinese Journal of Applied Ecology, 13, 1099-1103. (in Chinese with English abstract) [陈利军, 武志杰, 姜勇, 周礼恺 (2002). 与氮转化有关的土壤酶 活性对抑制剂施用的响应. 应用生态学报, 13，10991103.]

Chen SL, Wang JM, Pan YZ, Ma JY, Zhang JH, Zhang HS, Teng S (2012). Genetic analysis of seed germinability under submergence in rice. Chinese Bulletin of Botany, 47, 28-35. (in Chinese with English abstract) [陈孙禄, 王俊 敏, 潘佑找, 马健阳, 张建辉, 张红生, 滕胜 (2012). 水 稻萌发耐淹性的遗传分析. 植物学报, 47, 28-35.]

Chen Y, Yin YX, Chen XW (2011). Change of flood disasters in China since the 1880 s and some possible causes. Journal of Natural Resources, 26, 2110-2120. (in Chinese with English abstract) [陈荣, 尹义星, 陈兴伟 (2011). 19世纪 末以来中国洪涝灾害变化及影响因素研究. 自然资源 学报, 26, 2110-2120.]

Chérif M, Tirilly Y, Bélanger RR (1997). Effect of oxygen concentration on plant growth, lipidperoxidation, and receptivity of tomato roots to Pythium F under hydroponic conditions. European Journal of Plant Pathology, 103, 255-264.

Colmer TD, Voesenek LJ (2009). Flooding tolerance: Suites of plant traits in variable environments. Functional Plant Biology, 36, 665-681.

Cruickshank IAM, Perrin DR (1967). Studies on phytoalexins: $\mathrm{X}$. Effect of oxygen tension on the biosynthesis of pisatin and phaseollin. Journal of Phytopathology, 60, 335-342.

Dongen JV, Schurr U, Pfister M, Geigenberger P (2003). Phloem metabolism and function have to cope with low internal oxygen. Plant Physiology, 131, 1529-1543.

Dordas C, Hasinoff BB, Rivoal J, Hill RD (2004). Class-1 hemoglobins, nitrate and NO levels in anoxic maize cellsuspension cultures. Planta, 219, 66-72.

Drew MC, Lynch JM (1980). Soil anaerobiosis, microorganisms, and root function. Annual Review of Phytopathology, $18,37-66$.

Drew MC (1997). Oxygen deficiency and root metabolism: 
Injury and acclimation under hypoxia and anoxia. Annual Review of Plant Physiology \& Plant Molecular Biology, 48, 223-250.

Gao HB, Guo SR (2004). Effects of exogenous $\gamma$-aminobutyric acid on antioxidant enzyme activity and reactive oxygen content in muskmelon seedlings under nutrient solution hypoxia stress. Journal of Plant Physiology and Molecular Biology, 30, 651-659. (in Chinese with English abstract) [高洪波, 郭世荣 (2004). 外源 $\gamma$-氨基丁酸对营养液低 氧胁迫下网纹甜瓜幼苗抗氧化酶活性和活性氧含量的 影响. 植物生理与分子生物学学报, 30, 651-659.]

Geigenberger P (2003). Response of plant metabolism to too little oxygen. Current Opinion in Plant Biology, 6, 247256.

Geigenberger P, Fernie AR, Gibon Y, Christ M, Stitt M (2000). Metabolic activity decreases as an adaptive response to low internal oxygen in growing potato tubers. Biological Chemistry, 381, 723-740.

Gibbs DJ, Cho LS, Md IN, Silvia G, Takeshi F, Bassel GW, Correia CS, Françoise C, Theodoulou FL, Bailey-serres J, Holdsworth MJ (2011). Homeostatic response to hypoxia is regulated by the N-end rule pathway in plants. Nature, 479, 415-418.

Godber BL, Doel JJ, Sapkota GP, Blake DR, Stevens CR, Eisenthal R, Harrison R (2000). Reduction of nitrite to nitric oxide catalyzed by xanthine oxidoreductase. Journal of Biological Chemistry, 275, 7757-7763.

Gunther SS (1987). Agriculture Encyclopedia: Root Formation. Yangxian Hall, Tokyo, Japan. 921-927.

Guo SR (2011). Soilless Culture. China Agriculture Press, Beijing. (in Chinese) [郭世荣 (2011). 无土栽培学. 中国农 业出版社, 北京.]

Holtman WL, Duijn BV, Blaakmeer A, Blok C (2005). Optimalization of oxygen levels in root systems as effective cultivation tool. Acta Horticulturae, 697, 57-64.

Hu J, Zhou JB, Peng XX, Xu HH, Liu CX, Du B, Yuan HY, Zhu LL, He GC (2011). The Bphi008a gene interacts with the ethylene pathway and transcriptionally regulates $M A P K$ genes in the response of rice to brown planthopper feeding. Plant Physiology, 156, 856-872.

Huang B, Johnson JW, Nesmith S, Bridges DC (1994). Growth, physiological and anatomical responses of two wheat genotypes to waterlogging and nutrient supply. Journal of Experimental Botany, 45, 193-202.

Igamberdiev AU, Bykova NV, Shah JK, Hill RD (2010). Anoxic nitric oxide cycling in plants: Participating reactions and possible mechanisms. Physiologia Plantarum, 138, 393-404.

Ismail AM, Ella ES, Vergara GV, Mackill DJ (2010). Mechanisms associated with tolerance to flooding during germination and early seedling growth in rice (Oryza sativa). Annals of Botany, 103, 197-209.
Jia YX (2009). Studies on Physiological Regulation Function of Exogenous Spermidine on Cucumber Seedlings Tolerance to Hypoxia. PhD dissertation, Nanjing Agricultural University, Nanjing. (in Chinese with English abstract) [贾永 霞 (2009). 外源亚精胺提高黄瓜幼苗低氧胁迫耐性的 生理调节功能. 博士学位论文, 南京农业大学, 南京.]

Jia YX, Guo SR, Li J, Sun J, Huang BJ (2008). Effects of exogenous putrescine on polyamines and antioxidant system in cucumber seedlings under root-zone hypoxia stress. Acta Botanica Boreali-Occidentalia Sinica, 28, 1654 1662. (in Chinese with English abstract) [贾永霞, 郭世荣, 李娟, 孙锦, 黄保健 (2008). 外源腐胺对根际低氧胁迫 下黄瓜幼苗多胺和抗氧化系统的影响. 西北植物学报, 28, 1654-1662.]

Jin Q (2008). Micro-Nano bubble generating device. China Water Resources, (4), 72. (in Chinese) [金强 (2008). 微 纳米气泡发生装置. 中国水利, (4), 72.]

Jing L (2015). Root aeration improves growth and N accumulation in rice seedlings under low nitrogen. АОВ Plants, 7, 225-228.

Johannes W (1960). Plant Respiration Inclusive Fermentations and Acid Metabolism. Part 2. Springer-Verlag, Heidelberg, Germany. 114-148.

Kuan TL, Erwin DC (1980). Predisposition effect of water saturation of soil on phytophthora root rot of alfalfa. Phytopathology, 70, 981-986.

Ladygin VG (1999). Functional activity and chloroplast structure in leaves of Pisum sativum and Glycine max under conditions of root hypoxia and anoxia. Russian Journal of Plant Physiology, 46, 207-218.

Laura VM, Loreti E, Anna M, Amedeo A, Pierdomenico P (2010). Hormonal interplay during adventitious root formation in flooded tomato plants. The Plant Journal, 63, 551-562.

Licausi F, Kosmacz M, Weits DA, Giuntoli B, Giorgi FM, Voesenek LJ, Perata P, van Dongen JT (2011). Oxygen sensing in plants is mediated by an $\mathrm{N}$-end rule pathway for protein destabilization. Nature, 479, 419-422.

Licausi F, van Dongen JT, Giuntoli B, Novi G, Santaniello A, Geigenberger P, Perata P (2010). HRE1 and HRE2, two hypoxia-inducible ethylene response factors, affect anaeroic responses in Arabidopsis thaliana. The Plant Journal, 62, 302-315.

Liu HT, Li B, Shang ZL, Li XZ, Mu RL, Sun DY, Zhou RG (2004). Calmodulin is involved in heat shock signal transduction in wheat. Plant Physiology, 132, 1186-1195.

Ma YH, Guo SR, Du NS, Shan X, Sun J, Wang L, Wang Y, Shu S (2015). Effect of exogenous 24-epibrassinolide on nitrogen assimilation of cucumber seedlings under hypoxia stress. Journal of Nanjing Agricultural University, 38, 538-545. (in Chinese with English abstract) [马月花, 郭 世荣, 杜南山, 山溪, 孙锦, 王磊, 王颖, 束胜 (2015).

www.plant-ecology.com 
外源24-表油菜素内酯对低氧胁迫下黄瓜幼苗氮代谢的 影响. 南京农业大学学报, 38, 538-545.]

Magness JR (1920). Composition of gases in intercellular spaces of apples and potatoes. Botanical Gazette, 70, 308316.

Mi YF (2009). Research on Tolerance Evaluation and Physiological Mechanism of Kiwifruit Seedling to Root Zone Hypoxia. PhD dissertation, Northwest Agriculture and Forestry University, Yangling, Shaanxi. (in Chinese with English abstract). [米银法 (2009). 猕猴桃实生苗对根际 低氧胁迫的抗性评价及抗性生理机制研究. 博士学位 论文, 西北农林科技大学, 陕西杨凌.]

Morard P, Silvestre J (1996). Plant injury due to oxygen deficiency in the root environment of soilless culture: A review. Plant and Soil, 184, 243-254.

Nakano Y (2007). Response of tomato root systems to environmental stress under soilless culture. Japan Agricultural Research Quarterly, 41, 7-15.

Negi S, Ivanchenko MG, Muday GK (2009). Ethylene regulates lateral root formation and auxin transport in Arabidopsis thaliana. The Plant Journal, 55, 175-187.

Nichols MA, Woolley DJ, Christie CB (2002). Effect of oxygen and carbon dioxide concentration in the root zone on the growth of vegetables. Acta Horticulturae, (578), 119-122. doi: 10.17660/ActaHortic.2002.578.13.

Ober ES, Sharp RE (1996). A microsensor for direct measurement of $\mathrm{O}_{2}$ partial pressure within plant tissues. Journal of Experimental Botany, 47, 447-454.

Park JS, Ohashi K, Kurata K, Lee JW (2010). Promotion of lettuce growth by application of microbubbles in nutrient solution using different rates of electrical conductivity and under periodic intermittent generation in a deep flow technique culture system. European Journal of Horticultural Science, 75, 198-203.

Pei PG, Zhang JH, Zhu LF, Yu SM, Jin QY (2013). Research progress on effects of rhizosphere dissolved oxygen on root morphology and physiological characteristics in rice. China Rice, 19(2), 6-8. (in Chinese with English abstract) [裴鹏刚, 张均华, 朱练峰, 禹盛苗, 金千瑜 (2013). 根 际氧浓度调控水稻根系形态和生理特性研究进展. 中 国稻米, 19(2), 6-8.]

Rhoads DM, Subbaiah CC (2007). Mitochondrial retrograde regulation in plants. Mitochondrion, 7, 177-194.

Rolletschek H, Borisjuk L, Koschorreck M, Wobus U, Weber H (2002). Legume embryos develop in a hypoxic environment. Journal of Experimental Botany, 53, 1099-1107.

Rong GS, Tachibana S (1997). Effect of dissolved $\mathrm{O}_{2}$ levels in a nutrient solution on the growth and mineral nutrition of tomato and cucumber seedlings. Engei Gakkai Zasshi, 66, 331-337.

Sauter M (2013). Root responses to flooding. Current Opinion in Plant Biology, 16, 282-286.
Setter TL, Datta S (1997). Physiology and genetics of submergence tolerance in rice. Annals of Botany, 79, 67-77.

Shimamura S, Ryo Y, Nakamura T, Shinji S, Setsuko K (2011). Stem hypertrophic lenticels and secondary aerenchyma enable oxygen transport to roots of soybean in flooded soil. Annals of Botany, 106, 277-284.

Taiz L, Zeiger E (2010). Plant Physiology. 5th edn. Sinauer Associates, Massachusetts, USA.

Thani QA, Schaffer B, Liu GD, Vargas AI, Crane JH (2016). Chemical oxygen fertilization reduces stress and increases recovery and survival of flooded papaya (Carica papaya L.) plants. Scientia Horticulturae, 202, 173-183.

Vasellati V, Oesterheld M, Medan D, Loreti J (2001). Effects of flooding and drought on the anatomy of Paspalum dilatatum. Annals of Botany, 88, 355-360.

Wang GL, Semenza GL (1993). Characterization of hypoxiainducible factor 1 and regulation of DNA binding activity by hypoxia. Journal of Biological Chemistry, 268, 2151321518.

Wang T, Li J, Guo SR, Gao HB, Wang SP (2005). Effects of exogenous polyamines on the growth and activities of $\mathrm{H}^{+}$-ATPase and $\mathrm{H}^{+}$-PPase in cucumber seedling roots under hypoxia stress. Journal of Plant Physiology and Molecular Biology, 31, 637-642. (in Chinese with English abstract) [汪天, 李娟, 郭世荣, 高洪波, 王素平 (2005). 外源多胺对低氧胁迫下黄瓜幼苗根系生长及 $\mathrm{H}^{+}-\mathrm{ATP}$ 酶 和 $\mathrm{H}^{+}$-焦磷酸酶活性的影响. 植物生理与分子生物学学 报, 31, 637-642.]

Wang WQ, Zhang FS (2001). The physiological and molecular mechanism of adaptation to anaerobiosis in higher plants. Plant Physiology Communications, 37, 63-70. (in Chinese with English abstract) [王文泉, 张福锁 (2001). 高等植 物厌氧适应的生理及分子机制. 植物生理学通讯, 37, 63-70.]

Wang YJ, Gao C, Wang AQ, Wang YY, Zhang FY, Zhai JQ, Li XC, Su BD (2014). Temporal and spatial variation of exposure and vulnerability of flood disaster in China. Progressus Inquisitiones DE Mutatione Climatis, 10, 391398. (in Chinese with English abstract) [王艳君, 高超, 王 安乾, 王豫燕, 张飞跃, 翟建青, 李修仓, 苏布达 (2014). 中国暴雨洪涝灾害的暴露度与脆弱性时空变化 特征. 气候变化研究进展, 10, 391-398.]

Wei LK, Chen PW, Lu CA, Chen S, Ho THD, May YS (2009). Coordinated responses to oxygen and sugar deficiency allow rice seedlings to tolerate flooding. Science Signaling, 2, ra61. doi: 10.1126/scisignal.2000333.

Wilcox WF, Mircetich SM (1985). Effects of flooding duration on the development of Phytophthora root and crown rots of cherry. Phytopathology, 75, 562-565.

Xu CM, Wang DY, Chen S, Chen LP, Zhang XF (2012). Effect of aeration on root growth and nitrogen metabolism in rice. Chinese Journal of Rice Science, 26, 320-324. (in 
Chinese with English abstract) [徐春梅, 王丹英, 陈松, 陈丽萍, 章秀福 (2012). 增氧对水稻根系生长与氮代谢 的影响. 中国水稻科学, 26, 320-324.]

Xue XL, Yang WH, Zhang TZ (2017). Oxygen-increased and disinfectant technology of nutrient solution aerated by Micronano bubbles. Agriculture Engineering Technology, 37(1), 46-50. (in Chinese with English abstract) [薛晓莉, 杨文华, 张天柱 (2017). 营养液微纳米气泡增氧消毒技 术. 农业工程技术, 37(1), 46-50.]

Zhang JX (1994). Can early wilting of old leaves account for much of the ABA accumulation in flooded pea plants? Journal of Experimental Botany, 45, 1335-1342.

Zhang YY, Sun ZP, Liu GJ, Zhang C (2011). Effect of different root-zone aeration methods on tomato media characteristic. Acta Agriculturae Boreali-occidentalis Sinica, 20(4), 106-110. (in Chinese with English abstract) [张荣荣, 孙 周平, 刘广晶, 张超 (2011). 根区通气方式对番茄根际 气体环境及基质理化性质的影响. 西北农业学报, 20(4),
106-110.]

Zhao F, Zhang WJ, Zhang XF, Wang DY, Xu CM (2012). Effect of continuous aeration on growth and activity of enzymes related to nitrogen metabolism of different rice genotypes at tillering stage. Acta Agronomica Sinica, 38, 344-351. (in Chinese with English abstract) [赵锋, 张卫 建，章秀福，王丹英，徐春梅 (2012). 连续增氧对不同 基因型水稻分莧期生长和氮代谢酶活性的影响. 作物 学报, 38, 344-351.]

Zheng YB, Wang LP, Dixon M (2007). An upper limit for elevated root zone dissolved oxygen concentration for tomato. Scientia Horticulturae, 113, 162-165.

Zhu HJ (1992). Soil Geography. Higher Education Press, Beijing. (in Chinese) [ 朱鹤健 (1992). 土壤地理学. 高等教 育出版社, 北京.]

责任编委：王锁民 责任编辑: 李 敏 